\title{
Determination of the Single Nucleotide Polymorphisms C3435 and G2677T in MDR1 and C421A in BCRP in Blood Samples of Patients with Inflammatory Bowel Disease and Healthy Controls in the Swiss Population
} Felix Hammann¹, Petr Hruz ${ }^{1}$, Gerd Kullak-Ublick², Stephan R Vavricka ${ }^{3}$, Christoph Beglinger ${ }^{1}$, Jürgen Drewe ${ }^{1 *}$ and Heike Gutmann ${ }^{4}$

${ }^{1}$ Department of Gastroenterology \& Hepatology, University Hospital Basel, Switzerland

${ }^{2}$ Department of Clinical Pharmacology and Toxicology, University Hospital Zurich, Switzerland

${ }^{3}$ Department of Gastroenterology \& Hepatology, University Hospital Zurich, Switzerland

${ }^{4}$ Drug Metabolism and Pharmacokinetics, Novartis Institutes for BioMedical Research, Basel, Switzerland

\begin{abstract}
Aims: P-glycoprotein (P-gp, ABCB1, MDR1) and breast cancer resistance protein (BCRP, ABCG2) protect the luminal cells of the gastro-intestinal tract from potentially toxic substances. Genetic polymorphisms have previously been associated with disease susceptibility, severity, and treatment prognosis of inflammatory bowel disease. We investigated the prevalence of frequent single nucleotide polymorphisms of P-gp and BCRP in the Swiss population in healthy volunteers $(n=17)$ and patients newly diagnosed with Crohn's Disease $(C D, n=34)$ or Ulcerative Colitis (UC, $\mathrm{n}=38$ ).
\end{abstract}

Methods: DNA from peripheral blood cells was used to assess genotype and allele frequencies of MDR1 C3435T, MDR1 G2677T, and BCRP C421A.

Results: Weak associations for BCRP C421A ( $p<0.18)$ and MDR1 G2677T $(p<0.27)$ were seen in UC and a trend towards the wild type allele for MDR1 C3435T $(p<0.46)$. MDR1 3435CC / BCRP 421CC $\left(X^{2}: 1.0142, p<0.30\right)$ in UC and MDR1 2677G / BCRP 421A ( $\left.X^{2}: 1.5615, p<0.22\right)$ also weakly correlated with UC. Results for BCRP C421A in particular justify further study.

Conclusions: Trends towards certain alleles and haplotypes were seen. These merit further studies in larger subgroups (e.g. by disease stage, therapy refractory patients, etc.).

Keywords: Crohn's Disease; Ulcerative Colitis; Single Nucleotide Polymorphism; Haplotype; Genetics; Linkage

\section{Introduction}

Inflammatory bowel diseases (IBD) are a group of high-incidence inflammatory illness of the intestine, the two most prominent of which are ulcerative colitis (UC) and Crohn's disease (CD) [1]. Both share key clinical features (e.g., nausea, maldigestion and malnutrition, and associated extra-intestinal manifestations [2]), but also differ in their predominant location and the type of inflammation (UC is restricted to the mucosa of the colon whereas CD affects the whole length of the gastrointestinal tract and all three layers of the epithelium).

There is increasing evidence that the common cause of IBD is a malfunction of the intestinal immune system and screening efforts support the existence of genetic susceptibility loci [3], which may also affect treatment options and prognosis [4].

\section{P-glycoprotein (P-gp, MDR1)}

P-glycoprotein (P-gp) is a $170 \mathrm{kDa}$ transmembrane protein, member of the ATP binding cassette (ABC) family, and a well known mammalian efflux transporter that is expressed in many human organs with secretory or barrier function, including the liver, and the placenta [5]. It is also found on the endothelial capillaries of the brain [6], thereby contributing to the blood-brain-barrier function. P-gp is considered to protect the cell from xenobiotics and toxic compounds and accepts a wide variety of substrates, ranging from small organic ions to amino acids and even macromolecules like polysaccharides $[7,8]$. Other physiological functions are still subject of debate, but are thought to include regulation of apoptosis, stem-cell differentiation, cytokine modulation, and translocation of platelet-activating factor [9].
In the human gastrointestinal tract, $\mathrm{P}$-gp is expressed predominantly apically on the epithelium of small intestine and colon, but also in the small biliary and pancreatic ductules [10]. P-gp is therefore seen as a contributor to gut mucosal defense and reduced activity is thought to be a co-factor in IBD pathogenesis [11].

P-gp is encoded by the MDR1/ABCB1 gene, located on Chromosome 7q21.1, and spans over $100 \mathrm{~kb}$. However, MDR1 mRNA has a size of $4.7 \mathrm{kDa}$, implying that only a small percentage of the gene actually codes [12]. P-gp is currently the best studied ABC transporter and to date 50 single nucleotide polymorphisms (SNPs) have been identified, more than half of which reside in the coding region [13-15]. This interest stems from its ability to confer multidrug resistance in cancer cells by lowering the uptake of anti-cancer drugs [16]. Due to its promiscuity and localization, it also affects the bioavailability of many other drugs [17] and exposure to one of its substrates can render the cell resistant to a wide range of compounds [18].

*Corresponding author: Juergen Drewe, Professor, Department of Gastroenterology, University Hospital of Basel, Petersgraben 4, CH-4031 Basel, Switzerland, Tel: +41-61-265 3848; Fax: +41-61-265 8581, Tel: 404-385-4427; E-mail: juergen.drewe@unibas.ch

Received September 16, 2011; Accepted January 07, 2012; Published January 11, 2012

Citation: Hammann F, Hruz P, Kullak-Ublick G, Vavricka SR, Beglinger C, Drewe $J$, et al. (2012) Determination of the Single Nucleotide Polymorphisms C3435 and G2677T in MDR1 and C421A in BCRP in Blood Samples of Patients with Inflammatory Bowel Disease and Healthy Controls in the Swiss Population. Metabolomics 2:104. doi:10.4172/2153-0769.1000104

Copyright: (c) 2012 Hammann F, et al. This is an open-access article distributed under the terms of the Creative Commons Attribution License, which permits unrestricted use, distribution, and reproduction in any medium, provided the original author and source are credited. 
Citation: Hammann F, Hruz P, Kullak-Ublick G, Vavricka SR, Beglinger C, Drewe J, et al. (2012) Determination of the Single Nucleotide Polymorphisms C3435 and G2677T in MDR1 and C421A in BCRP in Blood Samples of Patients with Inflammatory Bowel Disease and Healthy Controls in the Swiss Population. Metabolomics 2:104. doi:10.4172/2153-0769.1000104

Page 2 of 5

Most SNPs in the coding region of P-gp have a relatively low frequency $(<8 \%)$ [15]. With a reported prevalence of $34.3 \%$ in Caucasians and $16.9 \%$ in Asians, the SNP C3435T (exon 26) affecting the nucleotide binding domain (NBD) 2 is an exception [19]. Even though C3435T is a silent SNP, early studies [20] showed a decrease in duodenal MDR1 protein expression. Reasons for its effects are still subject of debate [21] and a possible link between this SNP and IBD is also inconclusive [12].

The tri-allelic G2677T/A SNP (Ala893Ser/Thr), known to decrease MDR1 transport activity, is also frequently assessed. There are indications that the MDR1 G2677T allele is in linkage disequilibrium with C3435T, offering a possible explanation for loss of activity associated with this silent SNP [22]. MDR1 G2677A is not equally well understood as its prevalence is very low (around 1\%) [12] and high sample sizes are needed to give valid estimates. Some authors therefore chose to exclude it in their studies $[23,24]$.

\section{Breast Cancer Resistance Protein (BCRP)}

Breast cancer resistance protein (BCRP, ABCP, MXR) is the product of the ABCG2 gene, located on chromosome 4q22 and spanning > $66 \mathrm{~kb}$. With reference to other dimer members of the ABC family of transporters, which consist of twelve transmembrane domains (TMD) and two ATP binding domains (ABD), BCRP has been characterized as a half-transporter, as it only has six TMDs and one ABD [25]. BCRP is expressed in the epithelium of the small intestine and small biliary ducts as well as in the breast and placenta [26]. Like P-gp, it is assumed to maintain functional barriers and has been shown to be a limiting factor in drug absorption and distribution, e.g. in topotecan, doxorubicin, and mitoxantrone $[27,28]$.

The non-synonymous C421A SNP (Q141K) affects the ABD of BCRP and substrate binding properties [29]. Its prevalence is quite high, with about $30 \%$ in Asian (particularly Han Chinese) and $>10 \%$ in Caucasian populations while it is rarely seen in African populations [30,31]. Strikingly, no associations between the SNP and intestinal expression of mRNA or protein could be found [32]. In vitro and in vivo studies, on the other hand, have shown this SNP to be disruptive of BCRP activity. Clinical trials with diflomotecan, a novel anticancer agent inhibiting topoisomerase I, showed decreased plasma concentration in patients heterozygous for this SNP compared to wild type [33,34]. Recently, the increased placental crossing of the antidiabetic agent glyburide (glibenclamide) has been demonstrated in stably transfected human embryonic kidney (HEK)-293 cells expressing the polymorphic ABCG2 (Q141K) [35].

\section{Synergisms of p-gp and BCRP}

$\mathrm{ABC}$ transporters, and P-gp and BCRP in particular, play an important role in tissue defense. Both are highly expressed in so-called side population (SP) cells, a line of primitive cells derived from bone marrow stem cells. SP cells have been detected in non-hematopoietic tissue and the two efflux pumps are thought to contribute strongly to tissue defense and regeneration in many organs [36]. A further synergism between P-gp and BCRP lies in their overlapping substrate affinity, for example the anti-cancer agent doxorubicin [37], the $\alpha_{1}$-receptor antagonist alfuzosin, and the histamine H2-receptor antagonist cimetidine [38]. Also, recent work by Tai et al. [39] indicates that both are involved in the clearance of the neurotoxic amyloid beta from the brain, thereby protecting individuals from Alzheimer's disease. It may suggest considering these two efflux pumps together in studies of pharmacokinetics or pathogenesis.

\section{Haplotype studies}

Haplotypes of MDR1 and BCRP have been reported to be associated with different inflammatory disorders of the gut. Urcelay et al. [40], for example, have identified a susceptibility haplotype (2677T / G3435) for CD. Fiedler et al. [41] found a similar association, most notably for the MDR1 2677GG / 3435TT haplotype with UC, but not for CD The haplotypes investigated by Ho et al. [23] showed positive (MDR1 G2677 / 3435T) and negative (MDR1 2677T / C3435) correlations with UC, and confirmed the findings of Fiedler et al. [42] Haplotypes including BCRP C421A have been less frequently assessed and no associations with a combined IBD endpoint are known of to date.

\section{Methods and Materials}

\section{Subjects}

We recruited a total of 89 unrelated volunteers ( 54 female, 35 male; age: 49.9 years \pm range; weight: $72.3 \mathrm{~kg} \pm$ range; height: 1.68 $\mathrm{m} \pm$ range; BMI: $25.5 \mathrm{~kg} / \mathrm{m}^{2} \pm$ range) in a series of intestinal mucosa biopsies and blood samples taken between 2001 and 2007 as part of a regular diagnostic procedure. Diagnosis of UC and CD were according to current clinical knowledge and based on radiological, endoscopic, and histopathological assessment [43]. The study was approved by the local ethics committee (Ethik-Kommission Beider Basel, EKBB) and informed consent was obtained by all volunteers.

\section{Genotyping}

Genomic DNA was isolated from peripheral EDTA-blood using the QIAamp DNA blood Kit (Quiagen, Hilden, Germany). We performed TaqMan analysis on a 7900HT Sequence Detection System (Applied Biosystems, Rotkreuz, Switzerland). $1 \mu \mathrm{l}$ of $10 \mathrm{ng} / \mu \mathrm{l}$ of genomic DNA was added in a well for a multiplex allelic discrimination assay along with $9 \mu$ l solution consisting of Applied Biosystems TaqMan MasterMix, forward primer, reverse primer, probes specific for the SNP being examined (see below), and RNase-free water. Samples were pipetted onto a 384-well PCR plate (Treff Lab'). The probe stock solutions $(=100 \mathrm{pmol} / \mu \mathrm{l})$ were diluted to a concentration of $2 \mathrm{pmol} / \mu \mathrm{l}$ for allelic discrimination analysis. During a run, samples were heated to $50^{\circ} \mathrm{C}$ for 2 minutes, then subjected to $95^{\circ} \mathrm{C}$ for initial denaturation. Then, 40 cycles of a two-step PCR were performed at $95^{\circ} \mathrm{C}$ for $15 \mathrm{~s}$ and $60^{\circ} \mathrm{C}$ for $60 \mathrm{~s}$

\section{Primers and probes}

The primer set for BCRP C421A was designed with Primer Express software (Version 2.0, Applied Biosystems) and ordered at Invitrogen (Carlsbad, CA, USA). The sequences for the probes were taken from work by Korenaga et al. [44] Table 1. For MDR1 G2677T, a custom

\begin{tabular}{|c|c|}
\hline & sequence \\
\hline probe 1 & 5'-FAM-CTGCTGAGAACTGTAAGT-MGB-3' \\
\hline probe 2 & 5'-VIC'-CTGCTGAGAACTTTAAGT-MGB-3' \\
\hline forward primer & 5'-TGTTGTGATGGGCACTCTGAC-3' \\
\hline reverse primer & 5'-TCATAGTTGTTGCAAGCCGAA-3` \\
\hline \multicolumn{2}{|c|}{ Artificial templates } \\
\hline $\begin{array}{l}\text { positive control } \\
\text { (C allele) }\end{array}$ & $\begin{array}{l}\text { 5'-TCATAGTTGTTGCAAGCCGAACTGCT } \\
\text { GAGAACTGTAAGTGTCAGAGTGCCCAT } \\
\text { CACAACA-3' }\end{array}$ \\
\hline $\begin{array}{l}\text { positive control } \\
\text { (A allele) }\end{array}$ & $\begin{array}{l}\text { 5'-TCATAGTTGTTGCAAGCCGAACTGC } \\
\text { TGAGAACTTTAAGTGTCAGAGTGCCCA } \\
\text { TCACAACA-3' }\end{array}$ \\
\hline
\end{tabular}

Table 1: Primers and Probes used for detection of the Breast Cancer Resistance Protein single nucleotide polymorphism C421A. 
Citation: Hammann F, Hruz P, Kullak-Ublick G, Vavricka SR, Beglinger C, Drewe J, et al. (2012) Determination of the Single Nucleotide Polymorphisms C3435 and G2677T in MDR1 and C421A in BCRP in Blood Samples of Patients with Inflammatory Bowel Disease and Healthy Controls in the Swiss Population. Metabolomics 2:104. doi:10.4172/2153-0769.1000104

Page 3 of 5

assay ordered from Applied Biosystems. The MDR1 C3435T SNP was assessed with primers and probes according to work by Eap et al. [45].

\section{Statistical analysis}

We calculated the distribution of genotypes from the allele frequencies and compared our observations with distributions expected from an assumed Hardy-Weinberg equilibrium using Pearson's $\mathrm{X}^{2}$ test with two degrees of freedom $(\mathrm{df}=2)$. A $\mathrm{p}$ value $<0.05$ was considered statistically significant. All evaluations were performed using Gnu R (http://r-project.org, version 2.8.1) on Microsoft Windows.

\section{Results and Discussion}

\section{Determination of genotypes for BCRP C421A, MDR1 C3435T, and MDR1 G2677T}

Distributions of all genotypes were calculated according to the Hardy-Weinberg equilibrium. We determined allele frequencies for the individual patient groups (CD, UC) and a combination of both patient groups (IBD). Odds ratios (OR) are given with a $95 \%$ confidence interval (CI) (See Table 2).

\section{MDR1 C3435T}

Wild type and mutant alleles were distributed equally in healthy controls. This finding is in accordance with previously published studies [46]. A slight, but statistically insignificantly increased value of $54 \%$ in the mutant allele $\mathrm{T}$ was only seen in patients with UC (OR: 1.76, CI: $0.30-9.78, \mathrm{p}<0.46)$. Glas et al. [47] and Potocnik et al. [24] have reported similar ratios. No difference was seen for CD (OR: 1.36, CI: $0.25-6.50, p<0.73$ ) or the combined endpoint IBD (OR: 1.53 , CI: $0.31-6.20, \mathrm{p}<0.5)$.

\section{MDR1 G2677T}

Although this SNP is actually tri-allelic, we limited ourselves to the $\mathrm{T}$ mutant allele due to our relatively small sample size. Other groups have done the same $[23,24]$. At $85 \%$, the wild type allele was more prevalent than the mutant allele in healthy controls. Compared to this, an association was seen with the wild type allele in UC (93\%, OR: 0.42 , CI: $0.08-2.20, \mathrm{p}<0.27)$ but no difference in either CD (OR: $0.65, \mathrm{CI}$ : $0.15-3.04, \mathrm{p}<0.52$ ) or the combined endpoint IBD (OR: 0.53, CI: $0.14-2.27, \mathrm{p}<0.33)$

\section{BCRP C421A}

The wild type was far more abundant (94\%) than the mutant allele. There is a clear trend towards the mutant allele in UC (OR: 3.51, CI: $0.63-37.03, \mathrm{p}<0.18$ ), albeit not a significant one. Patients with $\mathrm{CD}$ (OR: 1.68, CI: $0.27-18.47, \mathrm{p}<0.71$ ) and the combined group of IBD patients (OR: $2.48, \mathrm{CI}: 0.50-24.43, \mathrm{p}<0.35$ ) showed a similar tendency towards the A allele. The lack of significance may be due to the small sample population size and hence low statistical power.

\section{Haplotype analysis}

We investigated the associations of combined haplotypes of MDR1 and BCRP SNPs with special attention to the haplotypes previously reported on by other authors $[40,41,45]$. Most strikingly, we found no occurrence of the MDR $1^{\star} 2$ haplotype within any of the subgroups. The strongest association of a BCRP haplotype was for homozygous MDR1 3435CC / BCRP 421CC ( $\left.\mathrm{X}^{2}: 1.0142, \mathrm{p}<0.30\right)$ in UC and MDR1 2677G / BCRP 421A ( $\left.\mathrm{X}^{2}: 1.5615, \mathrm{p}<0.22\right)$, also in UC. It should be stressed that the latter combinations of loci are haplotypes only in a looser definition of the term as they are spread over different chromosomes.

\section{Conclusions}

We investigated the prevalence of the SNPs MDR1 C3435T, MDR1 G2677T, and BCRP C421A in blood samples from a Swiss population of healthy volunteers and patients suffering from CD or UC. Genotype and allele frequencies are similar to those found in other European populations. Although the effect of BCRP C421A on IBD is still poorly

\begin{tabular}{|c|c|c|c|c|c|c|c|}
\hline & \multirow[t]{2}{*}{ Group } & \multicolumn{3}{|c|}{ Genotype frequencies } & \multicolumn{2}{|c|}{ Allele frequencies } & \multirow{2}{*}{$\begin{array}{l}\text { p-value } \\
\text { (OR; 95\% CI) }\end{array}$} \\
\hline & & $C C$ & $C A$ & $A A$ & C & $A$ & \\
\hline \multirow{4}{*}{ BCRP C421A } & Controls & $15(0.88)$ & $2(0.12)$ & $0(0.00)$ & 0.94 & 0.06 & \\
\hline & $U C$ & $23(0.68)$ & $10(0.29)$ & $1(0.03)$ & 0.82 & 0.18 & $\begin{array}{l}0.18 \\
(3.51 ; 0.63-37.03)\end{array}$ \\
\hline & $C D$ & $31(0.82)$ & $7(0.18)$ & $0(0.00)$ & 0.91 & 0.09 & $\begin{array}{l}0.71 \\
(1.68 ; 0.27-18.47)\end{array}$ \\
\hline & $I B D$ & $54(0.75)$ & $17(0.24)$ & $1(0.01)$ & 0.91 & 0.09 & $\begin{array}{l}0.35 \\
(2.48 ; 0.50-24.43)\end{array}$ \\
\hline \multirow{5}{*}{ MDR1 C3435T } & & CC & $C T$ & $T T$ & C & $T$ & \\
\hline & Controls & $4(0.24)$ & $9(0.53)$ & $4(0.24)$ & 0.50 & 0.50 & \\
\hline & $U C$ & $5(0.15)$ & $21(0.62)$ & $8(0.24)$ & 0.46 & 0.54 & $\begin{array}{l}0.46 \\
(1.76 ; 0.30-9.78)\end{array}$ \\
\hline & $C D$ & $7(0.17)$ & $23(0.61)$ & $8(0.21)$ & 0.49 & 0.51 & $\begin{array}{l}0.73 \\
(1.36 ; 0.25-6.50)\end{array}$ \\
\hline & $I B D$ & $12(0.17)$ & $44(0.61)$ & $16(0.22)$ & 0.49 & 0.51 & $\begin{array}{l}0.50 \\
(1.53 ; 0.31-6.20)\end{array}$ \\
\hline \multirow{5}{*}{ MDR1 G2677T } & & GG & $G T$ & $T T$ & G & $T$ & \\
\hline & Controls & $12(0.71)$ & $5(0.29)$ & $0(0.00)$ & 0.85 & 0.15 & \\
\hline & $U C$ & $29(0.93)$ & $5(0.15)$ & $0(0.00)$ & 0.93 & 0.07 & $\begin{array}{l}0.27 \\
(0.42 ; 0.08-2.20)\end{array}$ \\
\hline & $C D$ & $30(0.79)$ & $7(0.18)$ & $1(0.03)$ & 0.88 & 0.12 & $\begin{array}{l}0.52 \\
(0.65 ; 0.15-3.04)\end{array}$ \\
\hline & $I B D$ & $59(0.82)$ & $12(0.17)$ & $1(0.01)$ & 0.88 & 0.12 & $\begin{array}{l}0.33 \\
(0.53 ; 0.14-2.27)\end{array}$ \\
\hline
\end{tabular}

Table 2: Genotype and allele frequencies of BCRP C421A, MDR1 C3435T, and MDR1 G2677T in UC ( $=34)$, CD ( $=38)$, IBD ( $=72)$, and healthy controls ( $n=17)$. All groups are in Hardy-Weinberg equilibrium, $\mathrm{OR}=$ odds ratio; $\mathrm{Cl}=$ confidence interval 
Citation: Hammann F, Hruz P, Kullak-Ublick G, Vavricka SR, Beglinger C, Drewe J, et al. (2012) Determination of the Single Nucleotide Polymorphisms C3435 and G2677T in MDR1 and C421A in BCRP in Blood Samples of Patients with Inflammatory Bowel Disease and Healthy Controls in the Swiss Population. Metabolomics 2:104. doi:10.4172/2153-0769.1000104

understood, the mutant allele showed the strongest correlation with UC of all SNPs in this article. An analysis in a larger sample of the population may reveal a statistically significant connection.

In our survey of haplotypes, we found no cases of MDR1 2677T / G3435. However, our results justify further research of the prevalence of the haplotypes MDR1 C3435T / BCRP C421A and MDR1 G2677T / BCRP C421A, both of which were weakly associated with susceptibility to UC. Again, a larger sample size would be desirable.

Data on the role of BCRP C421A in disease pathogenesis is still scarce, although this is increasingly coming into focus. Its pathogenetic potential has been recently demonstrated in a study in the Han Chinese population, showing a strong association between C421A and susceptibility to gout [48]. On the other hand, no association with the risk for colorectal cancer (for which UC are a known risk factor) could be demonstrated in an analysis of the Danish population [49]. The effects of BCRP C421A in disease remain ambivalent.

MDR1 as a candidate gene has received more attention in the past. In line with our findings of a weak association of the wild type $2677 \mathrm{G}$ is a current analysis of the Canterbury IBD project [50]. Ardizzone et al. [51] found no overall correlation of MDR1 C3435T or G2677T with IBD. They did, however, show an association of C3435T a subtype of CD (ileo-colonic CD). This selective analytical subgroup approach seems very sensible, given the generally weak associations of single genetic variants or haplotypes, as a way to increase sensitivity without the need of very large sample sizes. Unfortunately, the clinical information available to us was not detailed enough to allow for such an analysis. This, of course, is largely due to the size of the general Swiss population itself. Drawing greater sample sizes would involve a considerably longer sampling period and involvement of more centers on the national level. It is questionable that sufficient homogeneity as to stage of disease, treatment history, and so on, can be achieved in such a small population.

The etiology and pathogenesis of IBD remains poorly understood. The many factors known to influence disease susceptibility and phenotype cannot be pinned down to any single SNP, nor is any haplotype likely to discriminate the many facets of these diseases [52]. However, knowledge of the activity of efflux transporters at various stages of disease and in different populations will ultimately aid in the pathogenetic understanding and improved individualized therapy based on pharmacogenetic principles. Further studies could focus on patient subgroups based on disease progression and response to treatment.

\section{References}

1. Swidsinski A, Ladhoff A, Pernthaler A, Swidsinski S, Loening-Baucke V, et al (2002) Mucosal flora in inflammatory bowel disease. Gastroenterology 122: 44 54.

2. Ardizzone S, Puttini PS, Cassinotti A, Porro GB (2008) Extraintestinal manifestations of inflammatory bowel disease. Dig Liver Dis 40: S253-S259.

3. Xavier RJ, Podolsky DK (2007) Unravelling the pathogenesis of inflammatory bowel disease. Nature 448: 427-434.

4. Torok HP, Goke B, Konrad A (2008) Pharmacogenetics of Crohn's disease. Pharmacogenomics 9: 881-893.

5. Huls M, Russel FG, Masereeuw R (2008) The role of ATP binding cassette transporters in tissue defense and organ regeneration. J Pharmacol Exp Ther 328: 3-9.

6. Cordon-Cardo C, O'Brien JP, Boccia J, Casals D, Bertino JR, et al. (1990) Expression of the multidrug resistance gene product (P-glycoprotein) in human normal and tumor tissues. J Histochem Cytochem 38: 1277-1287.
7. Petraccia L, Onori P, Sferra R, Lucchetta MC, Liberati G, et al. (2003) MDR (multidrug resistance) in hepatocarcinoma clinical-therapeutic implications. Clin Ter 154: 325-335

8. Zhou SF (2008) Structure, function and regulation of P-glycoprotein and its clinical relevance in drug disposition. Xenobiotica 38: 802-832.

9. Mizutani T, Masuda M, Nakai E, Furumiya K, Togawa H, et al. (2008) Genuine functions of P-glycoprotein (ABCB1). Curr. Drug Metab 9: 167-174.

10. Thiebaut F, Tsuruo T, Hamada H, Gottesman MM, Pastan I, et al. (1987) Cellular localization of the multidrug-resistance gene product $\mathrm{P}$-glycoprotein in normal human tissues. Proc Natl Acad Sci USA 84: 7735-7738.

11. Ho GT, Moodie FM, Satsangi J (2003) Multidrug resistance 1 gene (P-glycoprotein 170): an important determinant in gastrointestinal disease? Gut 52: 759-766.

12. Annese V, Valvano MR, Palmieri O, Latiano A, Bossa F, et al. (2006) Multidrug resistance 1 gene in inflammatory bowel disease: a meta-analysis. World $J$ Gastroenterol 12: 3636-3644

13. Kerb R, Hoffmeyer S, Brinkmann U (2001) ABC drug transporters: hereditary polymorphisms and pharmacological impact in MDR1, MRP1 and MRP2. Pharmacogenomics 2: 51-64.

14. Sparreboom A, Danesi R, Ando Y, Chan J, Figg WD (2003) Pharmacogenomics of $A B C$ transporters and its role in cancer chemotherapy. Drug Resist Updat 6: 71-84.

15. Wang D, Sadee W (2006) Searching for polymorphisms that affect gene expression and mRNA processing: example ABCB1 (MDR1). AAPS J 8 E515-E520.

16. Gerlach JH, Endicott JA, Juranka PF, Henderson G, Sarangi F, et al. (1986) Homology between P-glycoprotein and a bacterial haemolysin transport protein suggests a model for multidrug resistance. Nature 324: 485-489.

17. Hughes JR (2008) One of the hottest topics in epileptology: ABC proteins. Their inhibition may be the future for patients with intractable seizures. Neurol Res 30: $920-925$

18. Dhananjay P, Mitra AK (2006) MDR- and CYP3A4-Mediated Drug-Drug Interactions. J Neuroimmune Pharmacol 1: 323-339.

19. Komoto C, Nakamura T, Sakaeda T, Kroetz DL, Yamada T, et al. (2006) MDR1 haplotype frequencies in Japanese and Caucasian, and in Japanese patients with colorectal cancer and esophageal cancer. Drug Metab Pharmacokinet 21 126-132.

20. Hoffmeyer S, Burk O, von Richter O, Arnold HP, Brockmöller J, et al. (2000) Functional polymorphisms of the human multidrug-resistance gene: multiple sequence variations and correlation of one allele with P-glycoprotein expression and activity in vivo. Proc Natl Acad Sci USA 97: 3473-3478.

21. Sakaeda T (2005) MDR1 genotype-related pharmacokinetics: fact or fiction? Drug Metab Pharmacokinet 20: 391-414.

22. Kim RB, Leake BF, Choo EF, Dresser GK, Kubba SV, et al. (2001) Identification of functionally variant MDR1 alleles among European Americans and African Americans. Clin Pharmacol Ther 70: 189-199.

23. Ho GT, Nimmo ER, Tenesa A, Fennell J, Drummond H, et al. (2005) Allelic variations of the multidrug resistance gene determine susceptibility and disease behavior in ulcerative colitis. Gastroenterology 128: 288-296.

24. Potocnik U, Ferkolj I, Glavac D, Dean M (2004) Polymorphisms in multidrug resistance 1 (MDR1) gene are associated with refractory Crohn disease and ulcerative colitis. Genes Immun 5: 530-539.

25. Koshiba S, An R, Saito H, Wakabayashi K, Tamura A, et al. (2008) Human ABC transporters ABCG2 (BCRP) and ABCG4. Xenobiotica 38: 863-888.

26. Jonker JW, Smit JW, Brinkhuis RF, Maliepaard M, Beijnen JH, et al. (2000) Role of breast cancer resistance protein in the bioavailability and fetal penetration of topotecan. J Natl Cancer Inst 92:1651-1656.

27. Maliepaard M, van Gastelen MA, de Jong LA, Pluim D, van Waardenburg RC et al. (1999) Overexpression of the BCRP/MXR/ABCP gene in a topotecanselected ovarian tumor cell line. Cancer Res 59: 4559-4563.

28. Allen JD, Brinkhuis RF, Wijnholds J, Schinkel AH (1999) The mouse Bcrp1 Mxr/Abcp gene: amplification and overexpression in cell lines selected fo resistance to topotecan, mitoxantrone, or doxorubicin. Cancer Res 59:42374241. 
Citation: Hammann F, Hruz P, Kullak-Ublick G, Vavricka SR, Beglinger C, Drewe J, et al. (2012) Determination of the Single Nucleotide Polymorphisms C3435 and G2677T in MDR1 and C421A in BCRP in Blood Samples of Patients with Inflammatory Bowel Disease and Healthy Controls in the Swiss Population. Metabolomics 2:104. doi:10.4172/2153-0769.1000104

29. Yanase K, Tsukahara S, Mitsuhashi J, Sugimoto Y (2006) Functional SNPs of the breast cancer resistance protein-therapeutic effects and inhibitor development. Cancer Lett 234: 73-80.

30. de Jong FA, Marsh S, Mathijssen RH, King C, Verweij J, et al. (2004) ABCG2 pharmacogenetics: ethnic differences in allele frequency and assessment of influence on irinotecan disposition. Clin Cancer Res 10: 5889-5894.

31. Kobayashi D, leiri I, Hirota T, Takane H, Maegawa S, et al. (2005) Functional assessment of ABCG2 (BCRP) gene polymorphisms to protein expression in human placenta. Drug Metab Dispos 33: 94-101.

32. Zamber CP, Lamba JK, Yasuda K, Farnum J, Thummel K, et al. (2003) Natural allelic variants of breast cancer resistance protein (BCRP) and their relationship to BCRP expression in human intestine. Pharmacogenetics 13: 19-28.

33. Sparreboom A, Gelderblom H, Marsh S, Ahluwalia R, Obach R, et al. (2004) Diflomotecan pharmacokinetics in relation to ABCG2 421C>A genotype. Clin Pharmacol Ther 76: 38-44.

34. Mizuarai S, Aozasa N, Kotani H (2004) Single nucleotide polymorphisms result in impaired membrane localization and reduced atpase activity in multidrug transporter ABCG2. Int J Cancer 109: 238-246.

35. Pollex EK, Anger G, Hutson J, Koren G, Piquette-Miller M (2010) Breast cancer resistance protein (BCRP)-mediated glyburide transport: effect of the C421A Q141K BCRP single-nucleotide polymorphism. Drug Metab Dispos 38: 740744.

36. Huls M, Russel FG, Masereeuw R (2009) The role of ATP binding cassette transporters in tissue defense and organ regeneration. J Pharmacol Exp Ther 328: 3-9.

37. Cascorbi I (2006) Role of pharmacogenetics of ATP-binding cassette transporters in the pharmacokinetics of drugs. Pharmacol Ther 112: 457-473.

38. Zhao R, Raub TJ, Sawada GA, Kasper SC, Bacon JA, et al. (2009) Breast Cancer Resistance Protein Interacts with Various Compounds in vitro, but Plays a Minor Role in Substrate Efflux at the Blood-Brain Barrier. Drug Metab Dispos 37: 1251-1258.

39. Tai LM, Loughlin AJ, Male DK, Romero IA (2009) P-glycoprotein and breast cancer resistance protein restrict apical-to-basolateral permeability of human brain endothelium to amyloid-beta. J Cereb Blood Flow Metab 29: 1079-1083.

40. Urcelay E, Mendoza JL, Martín MC, Mas A, Martínez A, et al. (2006) MDR1 gene: susceptibility in Spanish Crohn's disease and ulcerative colitis patients. Inflamm Bowel Dis 12: 33-37.
41. Fiedler T, Büning C, Reuter W, Pitre G, Gentz E, et al. (2007) Possible role of MDR1 two-locus genotypes for young-age onset ulcerative colitis but not Crohn's disease. Eur J Clin Pharmacol 63: 917-925.

42. Ostergaard M, Ernst A, Labouriau R, Dagiliené E, Krarup HB, et al. (2009) Cyclooxygenase-2, multidrug resistance 1 , and breast cancer resistance protein gene polymorphisms and inflammatory bowel disease in the Danish population. Scand J Gastroenterol 44: 65-73.

43. Nikolaus S, Schreiber S (2007) Diagnostics of inflammatory bowel disease. Gastroenterology 133:1670-1689.

44. Korenaga Y, Naito K, Okayama N, Hirata H, Suehiro Y, et al. (2005) Association of the BCRP C421A polymorphism with nonpapillary renal cell carcinoma. Int J Cancer 117: 431-434.

45. Eap CB, Fellay J, Buclin T, Bleiber G, Golay KP, et al. (2004) CYP3A activity measured by the midazolam test is not related to $3435 \mathrm{C}>\mathrm{T}$ polymorphism in the multiple drug resistance transporter gene. Pharmacogenetics 14: 255-260.

46. Palmieri $O$, Latiano A, Valvano R, D'Incà R, Vecchi M, et al. (2005) Multidrug resistance 1 gene polymorphisms are not associated with inflammatory bowe disease and response to therapy in Italian patients. Aliment Pharmacol Ther 22: $1129-1138$

47. Glas J, Török HP, Schiemann U, Folwaczny C (2004) MDR1 gene polymorphism in ulcerative colitis. Gastroenterology 126: 367.

48. Wang B, Miao Z, Liu S, Wang J, Zhou S, et al. (2010) Genetic analysis of ABCG2 gene C421A polymorphism with gout disease in Chinese Han male population. Hum Genet 127: 245-246.

49. Andersen V, , Ostergaard M, Christensen J, Overvad K, Tjønneland A, et al (2009) Polymorphisms in the xenobiotic transporter Multidrug Resistance 1 (MDR1) and interaction with meat intake in relation to risk of colorectal cancer in a Danish prospective case-cohort study. BMC Cancer 9: 407.

50. Huebner C, Browning BL, Petermann I, Han DY, Philpott M, et al. (2009) Genetic analysis of MDR1 and inflammatory bowel disease reveals protective effect of heterozygous variants for ulcerative colitis. Inflamm Bowel Dis 15 1784-1793.

51. Ardizzone S, Maconi G, Bianchi V, Russo A, Colombo E, et al. (2007) Multidrug resistance 1 gene polymorphism and susceptibility to inflammatory bowe disease. Inflamm Bowel Dis 13: 516-523.

52. Roses AD (2008) Pharmacogenetics in drug discovery and development: a translational perspective. Nat Rev Drug Discov 7: 807-817. 